\title{
Posterior Dislocation of the Hip in a 4-Year-0ld Boy
}

\author{
Serhat Mutlu1, Bulent Yucel1, Tahir Mutlu Duymus1, Baran Kömür1, Ozgur Karaman1, \\ Harun Mutlu2 \\ ${ }^{1}$ Department of Orthopaedics, Kanuni Sultan Suleyman Training and Research Hospital, Istanbul, Turkey \\ ${ }^{2}$ Department of Orthopaedics, Taksim Training and Research Hospital, Istanbul, Turkey \\ Email: serhatmutlu@hotmail.com
}

Received 13 December 2014; revised 27 December 2014; accepted 6 January 2015

Copyright (c) 2015 by authors and Scientific Research Publishing Inc.

This work is licensed under the Creative Commons Attribution International License (CC BY). http://creativecommons.org/licenses/by/4.0/

(c) (i) Open Access

\begin{abstract}
Traumatic hip dislocations occur in children below 15 years old. Just as in adults, posterior hip dislocations are 10 times more common than anterior hip dislocations. Traumatic hip dislocation in pediatric patients $<10$ years of age requires much less force than that in an adult, while in children over 10 years old, We reported a 4-year-old boy with traumatic hip dislocation. Closed reduction with the Bigelow manoeuvre was applied without general anesthesia in the Emergency room. Patient was followed up for 4 weeks in a hip spica cast. There were no problems at the 6-month follow-up examination. Traumatic hip dislocation in children is not a common event and is generally caused by minor trauma.
\end{abstract}

\section{Keywords}

Traumatic Hip Dislocation, Child, Posterior

\section{Introduction}

Traumatic hip dislocation is a relatively uncommon event in childhood. Only $5 \%-6 \%$ of dislocations occur in children aged below 15 years of age. The prognosis differs from dislocations in adults in terms of the mechanism of the trauma. Traumatic hip dislocation in pediatric patients $<10$ years of age requires much less force than that in an adult, while in children over 10 years old, it is generally the result of high-energy traffic accidents or motorsports-related activities [1]-[3]. Although boys are more frequently affected than girls, there are also some studies which have reported higher incidence in girls under the age of 5 years. Just as in adults, posterior hip dislocations are 10 times more common than anterior hip dislocations. Compared to adult cases, concomitant fracture with dislocation is not common, particularly in children under 6 years old. Patients are 
usually treated with closed reduction. It is also a severe injury that leads to a maximum number of complications, which include avascular necrosis, osteoarthosis, sciatic nerve injury and heterotrophic ossification [1]-[4].

\section{Case Report}

A 4-year-old boy presented at the Emergency Department with complaints of pain in the left hip and restricted motion of range following a fall at home. Physical examination revealed shortness in the left lower extremity, in addition to flexion, adduction and internal rotation deformity in the left hip. Vascular system and neurological evaluation revealed no pathological finding. Radiographic evaluation disclosed posterior traumatic hip dislocation (Figure 1). Closed reduction with the Bigelow manoeuvre was applied without general anesthesia in the Emergency room and concentric reduction was seen in the post-reductive views in a hip spica cast (Figure 2). Computerized tomography (CT) evaluation was made to ascertain any accompanying injury. No pathological finding was determined on the CT scan (Figure 3). The patient was discharged from hospital on the same day. There were no problems at the follow-up examination after two days. Patient was followed up for 4 weeks in a hip spica cast, then the cast was removed. There were no problems at the 6-month follow-up examination.

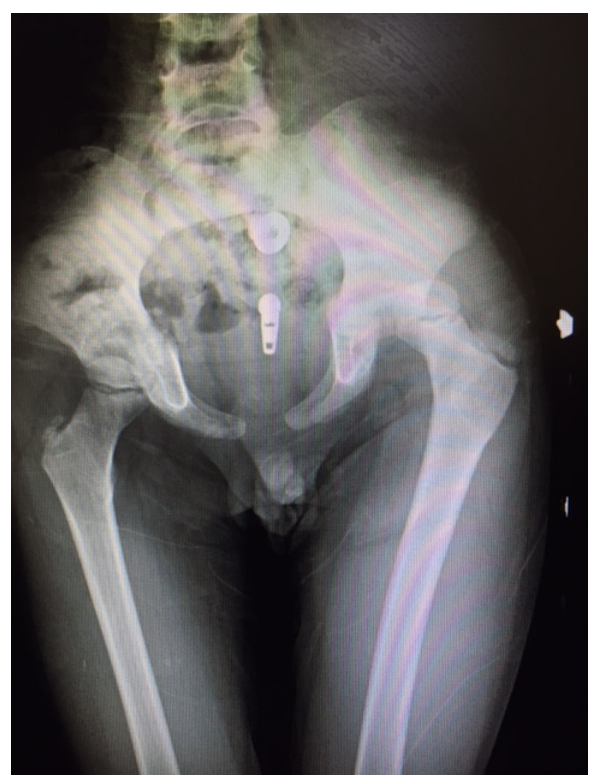

Figure 1. Bilateral hip AP radiograph on first presentation at the Emergency Department.

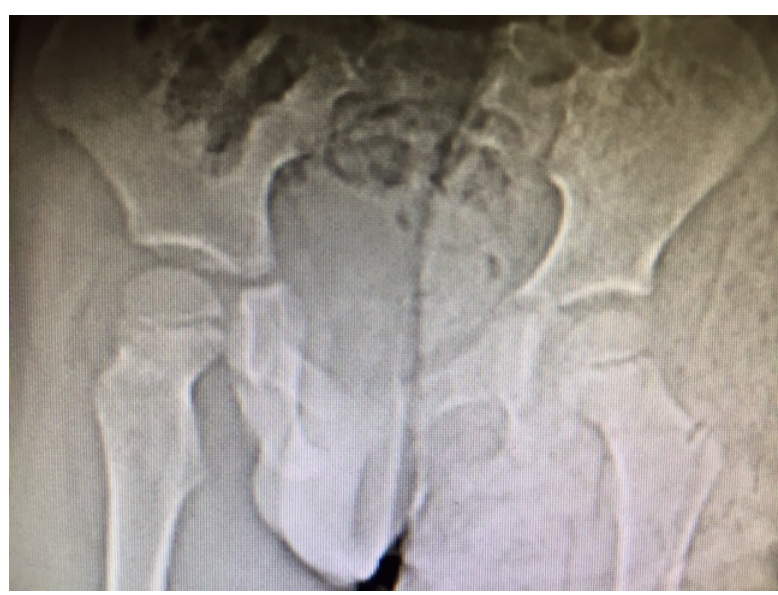

Figure 2. Bilateral hip AP radiograph with hip spica cast after reduction. 


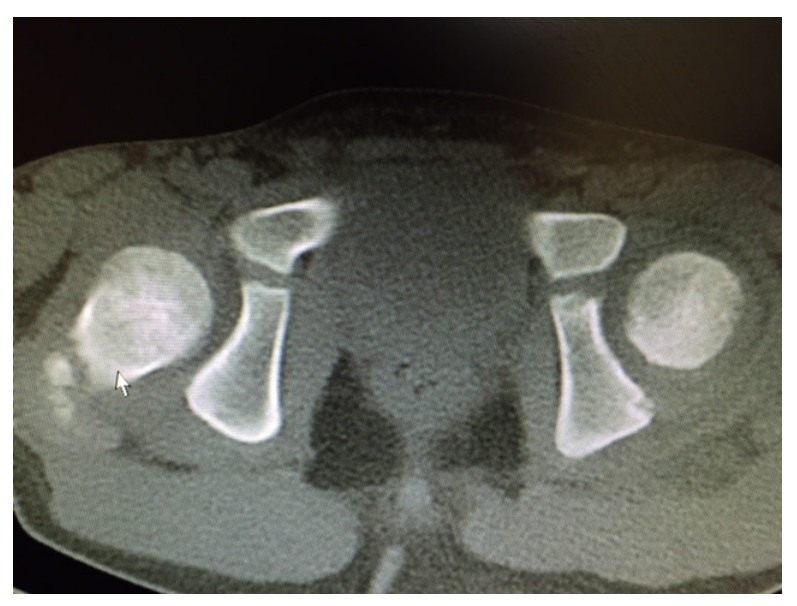

Figure 3. Bilateral hip CT images after reduction.

The patient's family was informed that data concerning his case would be submitted for publication.

\section{Discussion}

Traumatic hip dislocation is very rare in children. Cases in young children $<14$ years old, are less than $5 \%$ of adult cases. In addition, paediatric traumatic hip dislocation occurs from a small trauma. Accompanying fractures of the femoral head and acetabulum are more rare, and complication rates are lower than in an adult group. Boys are reported to be affected four times more than females. In literature, the patients have been evaluated in two groups, as those aged 2 - 8 years old with minor trauma and those aged 9 - 15 years old who have sustained the injury subsequent to major trauma such as motor vehicle accident. In adults, high energy trauma is the general rule. Standard anteroposterior and lateral pelvis radiographs should be taken [3]-[5].

In adults, MRI has been seen to be an effective evaluation method of accompanying injuries associated with acetabular fractures. F. Ivan et al. reported two cases, where MRI showed the true size of the posterior wall damage, which was not seen on plain radiographs or CT scans and thereby explained the etiology of postreduction instability [6]. Hearty et al. reported two cases of adolescent traumatic hip dislocations and posterior wall fractures in which radiography was not sufficient to show the extent of the posterior wall injury. Although most of these dislocations are posterior, M. Daniel et al. reported an anterior dislocation in a 9-year-old boy [4].

Complications that may develop following traumatic hip dislocations in children include avascular necrosis, traumatic arthritis, heterotopic ossification, sciatic nerve paralysis, coxa magna, femoroacetabular impingement. In one case, MRI more clearly characterized the injury. As the ossification of the posterior wall is completed during adolescence, MRI may be a useful tool in revealing these fractures and helping with surgical planning [7]-[11].

In avascular necrosis, the most important factors are the time until reduction not exceeding 24 hours, severe trauma in children over 6 years old and accompanying fracture. Although it has been stated that avascular necrosis generally develops within the first three years, these children should be closely monitored until their growth is complete.

Neurological damage has been reported to be observed in $20 \%$ of cases in the form of neuropraxia affecting the sciatic nerve and this usually recovers spontaneously [1] [11]-[13]. Early identification of hip dislocation affects the long-term prognosis. As particular problems develop when diagnosis is delayed or neglected in cases of multiple trauma, the pelvis of all multiple trauma patients should be evaluated radiographically. This is of particular importance when there is coma, fracture of the ipsilateral lower extremity, dislocation or fracture of the contralateral hip. In 1962, Funk studied different factors influencing the outcome of traumatic hip dislocation in children. It was reported that the fate of the femoral head seemed to be determined by the delay in reduction of the dislocated hip. It was concluded that permanent hip changes should be expected when reduction is delayed for more than $24 \mathrm{~h}$. Similar more recent reports have supported this view that earlier reduction results in a better outcome [2] [5]. Banskota et al. reported 8 cases of missed traumatic dislocation of the hip in 8 children treated by open reduction. All the patients had evidence of avascular necrosis [7]. Unlike adults, ectopic ossi- 
fication following hip dislocation without fracture in children has only been reported in cases associated with fracture dislocation or head injury [8].

Although rates of recurrent dislocation have been reported as higher in paediatric patient groups than in adults, this complication is rare. Capsular rupture or capsular failure are the etiology of recurrence. Therefore, patients with capsular rupture should be evaluated with arthrography and treated with surgical repair. Acute redislocation can be explained by hip instability when good reduction is not obtained because of a labral rupture or an osteoarticular fragment in the hip joint. Patients should be evaluated with CT and if there is any suspicion, treatment by open reduction must be applied [3] [14].

\section{Conclusion}

Traumatic hip dislocation in children is not a common event and is generally caused by minor trauma. As particular problems develop when diagnosis is delayed or neglected in cases of multiple trauma, the pelvis of all multiple trauma patients should be evaluated radiographically. Although complication rates are lower in adults, the time of reduction is important for a successful outcome.

\section{Competing Interests}

The authors have no conflicts of interest to disclose.

\section{Acknowledgements}

Thanks to the child's family for allowing the publication.

\section{References}

[1] Muratli, H.H., Dağli, C., Biçimoğlu, A. and Tabak, A.Y. (2004) Recurrent Traumatic Hip Dislocation in a Child. Acta Orthopaedica et Traumatologica Turcica, 38, 149-153.

[2] Singhal, R., Perry, D., Cohen, D. and Bruce, C. (2011) Delayed Diagnosis of Traumatic Hip Dislocation Mimicking Perthes Disease in a Child. BMJ Case Reports.

[3] Gürkan, V., Dursun, M., Orhun, H., Sever, G.B., Kiliçkap, C. and Berkel, T. (2006) Evaluation of Pediatric Patients with Traumatic Hip Dislocation. Acta Orthopaedica et Traumatologica Turcica, 40, 392-395.

[4] Avery 3rd, D.M. and Carolan, G.F. (2013) Traumatic Obturator Hip Dislocation in a 9-Year-Old Boy. The American Journal of Orthopedics, 42, E81-E83.

[5] Haverstock, J.P., Sanders, D.W., Bartley, D.L. and Lim, R.K. (2013) Traumatic Pediatric Hip Dislocation in a Toddler. The Journal of Emergency Medicine, 45, 91-94. http://dx.doi.org/10.1016/j.jemermed.2012.11.045

[6] Rubel, I.F., Kloen, P., Potter, H.G. and Helfet, D.L. (2002) MRI Assessment of the Posterior Acetabular Wall Fracture in Traumatic Dislocation of the Hip in Children. Pediatric Radiology, 32, 435-439. http://dx.doi.org/10.1007/s00247-001-0634-y

[7] Banskota, A.K., Spiegel, D.A., Shrestha, S., Shrestha, O.P. and Rajbhandary, T. (2007) Open Reduction for Neglected Traumatic Hip Dislocation in Children and Adolescents. Journal of Pediatric Orthopaedics, 27, 187-191. http://dx.doi.org/10.1097/BPO.0b013e31802c547e

[8] Sulaiman, A.R., Munajat, I. and Mohd, E.F. (2014) Outcome of Traumatic Hip Dislocation in Children. Journal of Pediatric Orthopaedics B, 23, 204-205. http://dx.doi.org/10.1097/BPB.0000000000000007

[9] Hughes, M.J. and D’Agostino, J. (1996) Posterior Hip Dislocation in a Five-Year-Old Boy: A Case Report, Review of the Literature, and Current Recommendations. The Journal of Emergency Medicine, 14, 585-590. http://dx.doi.org/10.1016/S0736-4679(96)00131-X

[10] Manner, H.M., Mast, N.H., Ganz, R. and Leunig, M. (2012) Potential Contribution of Femoroacetabular Impingement to Recurrent Traumatic Hip Dislocation. Journal of Pediatric Orthopaedics B, 21, 574-578. http://dx.doi.org/10.1097/BPB.0b013e328357bf04

[11] Hearty, T., Swaroop, V.T., Gourineni, P. and Robinson, L. (2011) Standard Radiographs and Computed Tomographic Scan Underestimating Pediatric Acetabular Fracture after Traumatic Hip Dislocation: Report of 2 Cases. Journal of Orthopaedic Trauma, 25, e68-e73. http://dx.doi.org/10.1097/BOT.0b013e3181f9a7ba

[12] Baker, J.F., Leonard, M., Devitt, B.M., Queally, J.M. and Noel, J. (2011) Traumatic Hip Dislocation in a 3-Year-Old Girl. Pediatric Emergency Care, 27, 1178-1179. http://dx.doi.org/10.1097/PEC.0b013e31823b0e71 
[13] Ciftdemir, M., Aydin, D., Ozcan, M. and Copuroglu, C. (2014) Traumatic Posterior Hip Dislocation and Ipsilateral Distal Femoral Fracture in a 22-Month-Old Child: A Case Report. Journal of Pediatric Orthopaedics B, 23, 544-548. http://dx.doi.org/10.1097/BPB.0000000000000089

[14] Rodriguez-Merchan, E.C. and Goddard, N.J. (2000) Traumatic Dislocation of the Hip. Clinical Orthopaedics and Related Research, 377, 2-3. 
Scientific Research Publishing (SCIRP) is one of the largest Open Access journal publishers. It is currently publishing more than 200 open access, online, peer-reviewed journals covering a wide range of academic disciplines. SCIRP serves the worldwide academic communities and contributes to the progress and application of science with its publication.

Other selected journals from SCIRP are listed as below. Submit your manuscript to us via either submit@scirp.org or Online Submission Portal.
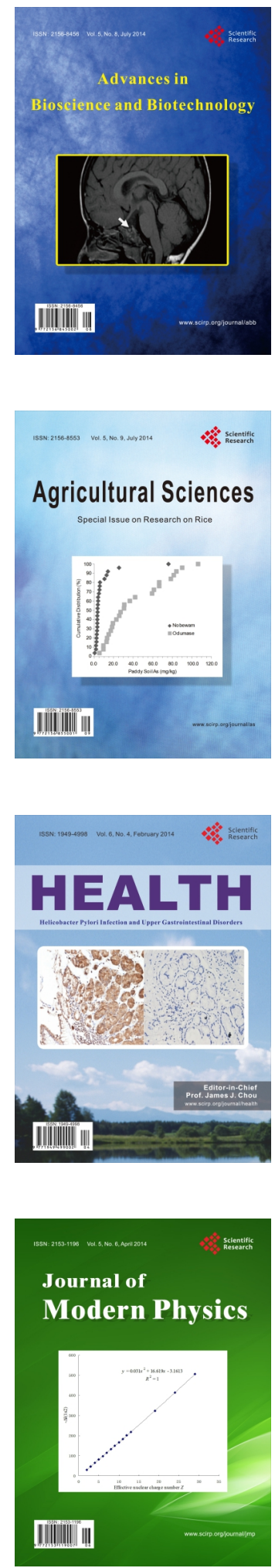
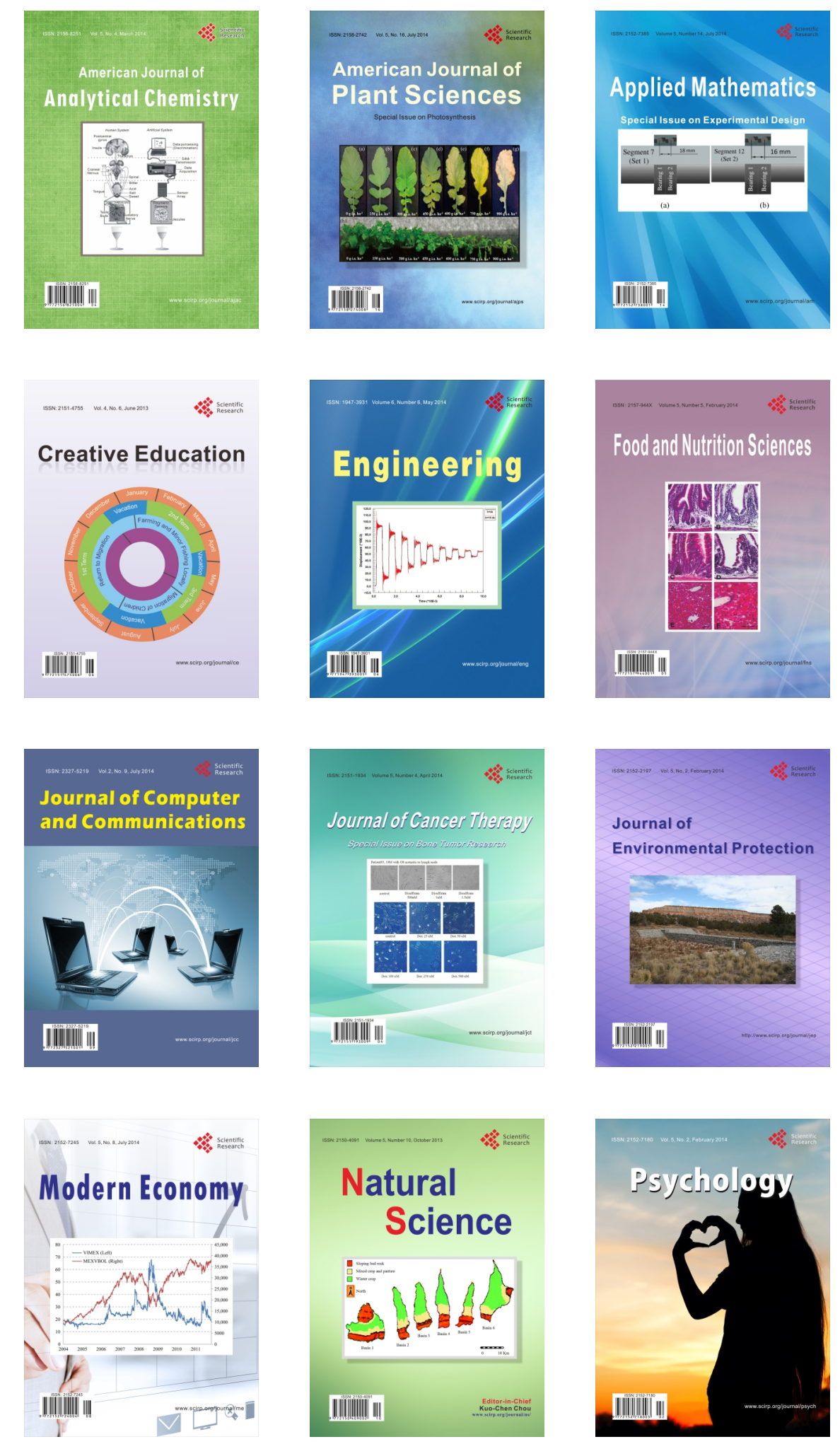